\title{
Why companies fail to respond to climate change: Collective inaction as an outcome of barriers to interaction
}

\author{
$\underline{\text { Tobias Finke }}^{1}$, Alan Gilchrist, Stefanos Mouzas \\ Department of Marketing, Lancaster University Management School, Lancaster LA1 4YX, United Kingdom
}

\begin{abstract}
The urgent need to combat climate change is now globally accepted. Collective action at a global level is the key ability to respond to the threat of climate change. No individual company alone has the necessary resources and capabilities to tackle the unprecedented challenge of climate change. Companies need to engage in give-and-take exchange relationships with other companies to address climate change. Research on how companies interact with each of their counterparts to respond to the challenge of climate change is limited. Existing research on climate raises questions about 1) how companies interact in response to climate change and 2) why companies fail to craft collective responses to climate change? In an attempt to shed light on these questions, we use the network approach as a theoretical perspective to account for the ever-increasing connectivity and interdependence in the business landscape and theorize on the consequences these phenomena may have for the study. The study is based upon an empirical investigation of public-private networks in Germany. Findings indicate that companies fail to collectively respond to climate change due to the multiplicity of interests of actors involved in the network which is aggravated by 1) economic reasoning; 2) weak actor bonds; and 3) differing perceptions of the rules of the game. As such, the present study contributes to our understanding of collective responses to the ever evolving challenge of climate change.
\end{abstract}

Key words: collective inaction, business networks, climate change

This research did not receive any specific grant from funding agencies in the public, commercial, or not-for-profit sectors.

\section{Introduction}

As climate change is now acknowledged as a global phenomenon (Oreskes, 2004; Meehl et $a l ., 2007)$, there has been a corresponding call for action to be taken at the organizational level to mitigate the effects of this environmental challenge, as part of a wider scale plea for change to occur at governmental, individual firm and even individual level (Giddens, 2009). In this paper, we suggest that no individual company alone has the necessary resources and capabilities to tackle the unprecedented challenge of climate change (Veal and Mouzas,

\footnotetext{
${ }^{1}$ Corresponding Author: Tobias Finke, E-Mail: t.finke@lancaster.ac.uk, Tel: +44 (0)1524 510671, Department of Marketing, Lancaster University Management School, Lancaster LA1 4YX, United Kingdom.
} 
2010). Companies thus need to engage in forms of collective action with other companies in in networks of exchange relationships (Easton and Håkansson, 1996; Gnyawali and Madhavan, 2001; Håkansson and Ford, 2002; Ritter, 2000), to address climate change (Brown, 1996; Pendergraft, 1998). In this study we investigate a case where this form of collective action, centered on responding to climate change, broke down and did not happen. We ask why and investigate the barriers to collective action in business networks. In doing so, we develop a theoretical framework to unveil the causes for failure of collective action centered on business network literature. Specifically, we concentrate on investigating and answering the following questions:

1. How do companies interact in response to climate change?

2. Why do companies fail to craft collective responses to climate change?

To allow a thorough answer of these questions, we turn now to developing an understanding of where the current research has taken us to.

\section{Previous Research}

\subsection{Business networks in the context of climate change}

In today's business landscape, companies find themselves embedded in networks of exchange relationships driven by processes of continuous interaction between individually significant and interdependent actors (Easton and Håkansson, 1996; Gnyawali and Madhavan, 2001; Håkansson and Ford, 2002; Håkansson and Waluszewski, 2002, 2007; Ritter, 2000). These exchange relationships are entered when actors perceive that value can be created and captured (Mouzas and Ford, 2009). Conflict in these exchange relationships is inevitable, particularly when actors' self-interests collide with collective interests of the organizations themselves, and of the wider societal groupings. The case of finding responses to climate change represents such a conflict. Self-interests, in this domain, are seen to motivate actors to free ride, where the best individual strategy may not result in a Pareto-optimal outcome (Nowak and Highfield, 2011). Common goods, such as a stable climate, are prone to contrary decision-making between self-interest and the best interest of the group. This is vividly demonstrated in the tragedy of commons, where individuals acting with self-interest independently behave contrary to the common good of all members, thus depleting common resources (Hardin, 1968). The tragedy of commons is inextricably linked with Olson's (1965) logic of collective action which suggests that rational actors will place the goals of the wider group of society over and above their individual goals.

However, there are difficulties inherent in engaging in collective action. Pendergraft (1998) argues for a link between a lack of collective action and the actual size of the collective. A similar congruence of thinking exists within the network literature where the interdependence of actors and the interactions between them is repeatedly highlighted as being increasingly problematic in direct relation to the size of the network and the number of actors involved (Ritter et al., 2004). Indeed, we argue that similarities can exist in terms of the barriers to both collective action and interaction such as scale, diversity of interest and the differing perspective of actors (Olson, 1982) which are inherent in larger collectives or networks. As Olson puts it: "in the absence of special arrangements or circumstances [...] large groups, at least if they are composed of rational individuals, will not act in their group interest" (1982, p. 18). 
Pertinent to this study and our focus on climate change, previous research on collective action suggests that disagreement among individuals may occur because of the scarcity of resources and the basic human belief of a fixed-resource pie (Veal and Mouzas, 2010; Bazerman et al., 1999). It is recognized that climate change represents such a case, since actors are not able to enlarge the planet and its resources are limited (Hardin, 1968). Here, we suggest that collective action is one possible outcome of business interaction. However, as we demonstrate in this paper conversely this may not always be the case.

Consequently, even the most ambitious climate change treaties have achieved very little, and, even more worryingly the increasing greenhouse gas emissions in the atmosphere continue to impose serious threats on natural, human and economic systems around the world, and would need to be reduced substantially over the coming years to stop climate disruption (IPCC, 2014; Stern, 2006).

It is important to consider some technical aspects of climate change in order to allow for a reliable investigation of interactions in response to climate change. Veal and Mouzas (2010) summarize the issue of climate change based on the Intergovernmental Panel on Climate Change Synthesis Report (IPCC, 2001) as following:

The Earth's climate system has demonstrably changed since the pre-industrial era. Human activities have increased the atmospheric concentrations of greenhouse gases and aerosols. An increasing body of observations gives a collective picture of a warming world and other changes in the climate system (Veal and Mouzas, 2010, p.423).

A broad consensus about climate change science, i.e. that it is real and man-made, exists in the research community (Oreskes, 2004; Meehl et al., 2007; Veal and Mouzas, 2010). Furthermore, it is recognized that it is still feasible to stabilize $\mathrm{CO}_{2}$ concentrations at acceptable levels (IPCC, 2014) and that the costs and risks resulting from contemporary inaction significantly exceed the costs of immediate climate change mitigation (Stern, 2006).

At the most basic level, responses to climate change can be either adaptation (responding) or mitigation (prevention). Both approaches are valid, since adaptation is necessary to handle changes that are already present and cannot be revoked, and mitigation is necessary to minimize long-term risks by stabilizing the atmospheric $\mathrm{CO}_{2}$ levels (Stern, 2006). Of significance in this study are two considerations of climate change, as suggested by Veal and Mouzas (2010):

1. It requires collective actions in various areas embedded in the economy and everyday life of people

2. Mounting a successful response is limited to a timeframe of 20 to 50 years due to the long atmospheric life span and cumulative nature of $\mathrm{CO}_{2}$, meaning that today's decisions can affect global climate changes for up to 50 years (IPCC, 2001)

We view these considerations in relation to climate change as being structural and physical constraints which are important contextual factors when investigating the barriers to consensus in climate change interactions.

This study uses the complexity driven by the two areas uncovered by Veal and Mouzas (2010) as the context in which interactions are and have to be made by organizational actors. Particularly, we aim to cut through this complexity by understanding how players get together in the game, to work together, to negotiate, to understand, and to listen. In order to achieve this outcome we need to uncover and understand what drives these actors in this global situation. 
The global nature and requirement of collective action to develop responses to climate change constructs a global network of stakeholders who care about the issue. The actors in this global climate change network include governments, international governance bodies, companies, non-governmental organizations, and research institutions (GlobeScan, 2006). Although all actors have a similar ability to influence the network, it needs to be considered that:

Governments and international governance bodies have a high level of internal interaction and influence between actors, whereas companies, non-governmental organizations, and research organizations experience within their actor groups and hence influence each other less (Veal and Mouzas, 2010, p.424).

Scholars seem not to have adequately addressed some of the most pressing questions about the appropriate responses to mitigate or adapt to climate change. Existing research on climate change has tended to focus on the operation of markets for carbon trading (e.g. Veal and Mouzas, 2011) and companies' individual responses (e.g. Okereke, 2007). However, there is a deficiency of discussion about how companies' as part of a wider network, may collectively respond (or not) to climate change.

The prevalence and significance of this gap becomes apparent when considering repeated calls for more in-depth research in this area. For example, Brett and Kopelman (2004) see the social dilemma of contributing to stop climate change as a topic where further study is required. Moreover, Veal and Mouzas (2012) request studies on markets for environmental governance that examine how cognitive and behavioral biases affect political and economic behavior (Bazerman, 1984; Hardie and MacKenzie, 2007; Leiserowitz, 2006; Sunstein, 2006; Tversky and Kahneman, 1981, 1986). Despite the rich contribution of behavioral approaches to our understanding of systematic biases and human errors, questions remain about the inherent barriers impeding collective action in business networks.

In order to account for the interdependence of actors, we adopt a network view on the activities of actors, rather than seeing them as individual and unitary (Welch and Wilkinson, 2004). It is this empirical lens which unveils the barriers preventing consensus in climate change interactions from being reached.

The network approach is used as a theoretical perspective to capture the ever increasing connectivity and interdependence in the business landscape. The network approach emphasizes that markets operate through complex institutional arrangements that enable exchange relationships amongst individually significant business actors (Easton and Araujo, 1994; Lazonick, 1991; Mouzas, 2006). These exchanges are possible through a process of interaction (Easton and Håkansson, 1996; Håkansson, 1982; Turnbull and Valla, 1986). Companies depend on the resources and capabilities of other actors to operate their business (Easton and Håkansson, 1996; Gnyawali and Madhavan, 2001; Håkansson and Ford, 2002). As a result markets can be considered as an interdependent array of companies involved in frequent and complex interactions with other market participants (Håkansson and Waluszewski, 2002, 2007; Ritter, 2000). We argue that the global climate change initiatives are akin to this complex array of actors, as depicted within the business network theory literature; however, what we are interested in are the actual multi-lateral interactions which take place within this network. 


\subsection{Barriers to collective action: The role of business interaction}

We aim to shed light on barriers against organizational level collective action in the case of climate change. In doing so, we suggest that we must first understand and highlight the underlying role of the process of business interaction and the barriers within, via the adoption of a business network approach.

A business interaction can be described as a self-serving process that involves trade-offs between individually recognized and inter-dependent actors to address short and long-term problems (Ford and Håkansson, 2006; Ford and Mouzas, 2013). The process of interaction allows companies to enable resources and to attain short and long-term benefits (Ford and Mouzas, 2013).

The resources of any business are interdependent and, therefore, do not operate in isolation. Physical, financial, human and technological resources of one actor are related to the respective resources of other actors (Ford and Håkansson, 2006). Through interaction these resources can be activated as counterparts to actors' own resources. Actors become more interdependent due to co-evolving resources enabled through the process of interaction. Hereby, strong relationships are built and can act as a multiplier of internal resources (ibid). Although business interaction is a fundamental process within a networked business landscape, its understanding remains limited (Ford and Håkansson, 2006), particularly in the case of climate change (Veal and Mouzas, 2010). We posit that a number of barriers exist that hinder or impede business interactions.

Firstly, interaction among businesses is driven and maintained for economic reasons (Håkansson, 1982). If economic rationality is absent, then business interaction is hindered. Secondly, interaction is a substantial process that involves the resources of counterparts. Financial resources (capital), physical resources (time, technologies, people) and informational resources (knowledge) are required to develop beneficial outcomes within interactions (Ford and Mouzas, 2010, 2013; Ritter and Gemünden, 2003). Thirdly, structure and design of rules of the game can influence the way that actors interact with each other (Felin et al., 2012; Veal and Mouzas, 2011). Nonetheless, business actors may elaborate responses that have an effect on the creation of new rules.

\section{Methods}

To investigate why companies fail to collectively respond to climate change, we engaged with relevant business actors in the public-private networks in Germany. More specifically, we attended a climate change panel discussion and conducted semi-structured interviews with stakeholders who made it clear by their participation that they care about climate change. This included representatives of a municipality (Mayor's Office, Economic Development Council, Climate Change Protection Office, Climate Protection Agency, and Urban Development \& Planning as well as an external advisor) and representatives of two companies (Environmental Officer and Head of Building \& Property Management). Through this process of research engagement, we enabled the identification of processes that would have remained undiscovered in experiment based decision research.

In this way, we respond to Wade-Benzoni et al. who suggest that "future research on institutional forces in ideologically based disputes is likely to be more fruitful if pursued in real-world conflicts" (2002, p.53). This methodological decision is supported by Yin's (2003) 
observation that field research is the appropriate research method to investigate a phenomenon in its real-life context. Investigating the behavior of business actors in networks of exchange relationships in Germany to mobilize collective action on climate change can be most suitably achieved through the case study research method (George and Bennett, 2005; Halinen and Törnroos, 2005; Perry, 1998; Yin, 2003).

\subsection{Data collection and analysis}

The data was collected between January and April 2015 through an empirical investigation of a public-private network initiated to develop collective responses to climate change. Furthermore, both companies are embedded in networks to exchange knowledge about responses to climate change (Figure 1 illustrates the actors' interconnectedness within the public-private network). The empirical evidence was collected through a panel discussion (to provide a general overview of the interactions) and five semi-structured interviews with key actors within each network were conducted to unveil the reasons for actors' behavior.



Figure 1: The public-private network

In the discussion section, we make several references to statements made by interviewees to support our arguments with empirical evidence. For clarity, we outline the network actor, the respondents interviewed and their specific role (names have been changed): 


\begin{tabular}{lll}
\hline Network actor & Name & Role \\
\hline Greenock & Harry & Head of Building \& Property Management \\
\hline Jack Fowler & Oliver & Environmental Officer \\
\hline Andor & Amelia & Mayor \\
\hline Andor & Olivia & Head of Economic Development \\
\hline Andor & Sophie & Head of Climate Protection Agency \\
\hline Andor & Emily & External Advisor \\
\hline Andor & Jessica & Head of Climate Protection Office \\
\hline Andor & Jack & Head of Urban Development \& Planning Office \\
\hline
\end{tabular}

Table 1: Network actors, names and roles

Questions as part of the semi-structured interviews broadly included: 1) What are the climate protection activities conducted by your institution/company; 2) With whom do you interact and what is the context of these interactions?; 3) From your perspective, what are the interests and objectives of your counterparts?; 4) Do you remember any cases of disagreements during these interactions, if yes why and how did you overcome/solve them?. In line with the nature of semi-structured interviews, these questions aimed to cover some general areas of interest for the researchers and were slightly different in all interviews. The data sources have been logged in a library of case documents to capture all relevant material (Veal and Mouzas, 2011). This process enabled handling multiple sources of evidence (Bennet and Elman, 2006; Numamgami, 1998). The data was collected with the aim of presenting a view of how businesses interact in response to climate change and what the reasons for the failed interaction in response to climate change are.

The analysis of the evidence involved a process of confrontation between empirical observations and theoretical concepts (Ragin and Becker, 1992; Yin, 2003). More specifically, the evidence has been examined, categorized, tabulated, tested, or otherwise recombined to draw robust empirical conclusions (Yin, 2003). In its early stages, the data analysis involved interplay between observations logged in the library of case documents and the conceptual framework, allowing iterative changes to the cases (Yin, 2003). Moreover, we borrow heavily from Håkansson and Johanson's (1992) ARA Model to develop our conceptual framework in order to reveal the process of interaction and the potential outcomes of it in relation to collective action.

According to the ARA Model the outcomes of interactions can be described through actor bonds, activity links and resource ties between actors (Håkansson and Snehota, 1995).

1. Actor bonds relate to interpersonal relationships between actors and the strength of actors bonds depends on 1) how actors see, know and feel close to each other; 2) how they trust, appreciate and influence each other and become mutually committed (Ford et al., 2008; see also Wilson and Jantrania, 1994; Wilkinson and Young, 1994; Huemer, 1998). Depending on the levels of these attributes, bonds between the actors will be weak/strong and may/may not influence the decisions of their counterparts (Ford et al., 2008). Moreover, actors appear to be an important factor when it comes to learning and teaching in relationships (Håkansson and Johanson, 2001). 
2. Activity links relate to the integration and co-ordination of activities (e.g. production, logistics, administration, deliveries, information handling) between actors (Ford et al., 2008). These more or less integrated and linked activities may lead to systematically similar and tightly linked behavior of companies (Richardson, 1972, Dubois, 1998). Depending on the strength, these links can have positive economic effects on the actors' involved (Ford et al., 2008).

3. Resource ties relate to "how the two actors' resources may become more or less adapted and more or less mutually tied together as their interaction develops. Specific mutual adaptations may concern tangible resources such as physical items of plant or equipment, but may also include intangible resources such as knowledge" (Ford et al., 2008, p.14). These resource ties are developed over time when actors adapt their resources (Hallen et al., 1991).

Furthermore, an analytical rather than statistical logic is applied to generalize the findings (Easton, 2010). This is in line with the aim to move beyond econometric analysis, in order to capture the interaction processes, since these interaction processes require description and explanation (Veal and Mouzas, 2012).

\subsection{The Study: A public-private network to protect the climate}

This case study is based on the interactions with a public-private network designed to enable collective responses to climate change. Within this public-private network, we concentrate on three key actors (all names have been changed): Andor, the municipality itself, and the two largest multi-billion dollar manufacturers situated within it, Greenock, and Jack Fowler (Figure 1).

Andor is a German city located within a metropolitan area in the south of Germany, with a population of over two million inhabitants. Size notwithstanding, Andor itself represents an interesting research case due to the high level of understanding of climate change from the majority of its 540 local companies. Indeed, in a recent study, over $90 \%$ of this total number affirmed that climate change and the environment were "important" (Panel Discussion, p.2, lines 12-21). However, and what is pertinent to this research paper, is the finding that only $22 \%$ of firms in the municipality sponsored study had any form of environmental management system (EMS) in place, or even the beginnings of a strategic approach such as an environmental certificate.

By way of historical context, Andor had been running a "most environmentally friendly company" competition for the prior five years, with Greenock and Jack Fowler jockeying for first and second place on an annual basis. Indeed, Andor itself had set a stringent goal of reducing $\mathrm{CO}_{2}$ emissions by a significant $40 \%$ by 2020, based on a benchmark level of 1990 .

Greenock is a manufacturer of metro, regional, suburban and high-speed trains, which also operates in the passenger transportation and signaling market. The company is one of the largest locomotive manufacturers with over 30,000 employees and operates worldwide. In addition to Greenock, the manufacturer Jack Fowler is part of the network. Jack Fowler is one of the largest producers of agricultural, construction and forestry machinery with over 67,000 employees worldwide. Both Greenock and Jack Fowler make multi-billion US\$ revenues annually and their operations have significant impact on the environment. As a response to the challenge of climate change they made the decision to enter into a climate protection cooperation with a city in which they both have manufacturing plants. 
Immersing ourselves within a network which was actively focused on enabling collective action for climate change enabled a holistic understanding of the issues we sought to engage with, in terms of answering the "how" and the "why" questions outlined above. Indeed, it was clear to see that for Andor, as a lead member of this public-private network, the network itself was the key component to achieve this goal due to the significance of collaborative working from all the actors involved.

Within each of the major actors within the network, there was a further level of what we would term a sub-network - constellations of 12 actors for both Greenock and Jack Fowler which was created by the municipality to promote knowledge exchange on energy efficiency measures as part of organizational responses to climate change. The goal the municipality set for these sub-networks to create opportunities for individual company level responses to climate change. The actors of the sub-networks possess the freedom to give input in the network and to conduct projects based on the resources they are willing to provide. All actors take their role within the network seriously and are open to share their experiences. These sub-networks met on an ongoing basis, twice per year.

After a period of three years Andor realized that knowledge exchange at the individual company level was not sufficient to reach their emissions reduction goal for 2020. As such, at this stage Andor instigated the design and implementation of the public-private network as a means to promote collective action. The actors in this network consisted of Greenock, Jack Fowler and the six municipality functions of Andor (Mayor's Office, Economic Development Council, Climate Change Protection Office, Climate Protection Agency, and Urban Development \& Planning as well as an external advisor).

Andor's interactions are executed by the mayor's office, the economic development council, the climate protection agency, the climate protection office, the urban development and planning office as well as an external advisor from another municipality which forms the Andor network. Actors of the Andor network interact in a mutual dialogue to develop the municipalities' climate protection strategy and measures. They are motivated by the joint goal of achieving the municipalities' climate protection doctrine and $\mathrm{CO}_{2}$ reduction scenario for 2020.

Actors within the Andor network have different roles but all have the common goal of $\mathrm{CO}_{2}$ reduction at the core of their remit. The climate protection office is responsible for promoting climate protection projects and engages with all actors within the municipality to jointly reduce $\mathrm{CO}_{2}$ emissions. The urban development and planning office interacts with the mayor's office to develop an urban landscape that promotes energy efficient buildings and ensures an air stream through the city that enables an acceptable climate in the city. The external advisor from another municipality provides examples of alternative approaches that have been implemented by their municipality. The climate protection agency is an office of the municipality to provide free and independent advice for citizens, the mayor's office, businesses and all other actors within the municipality regarding climate protection. Lastly, the economic development council promotes the climate protection and outlines possibilities for governmental grants and support to move towards a low carbon municipality.

The actors of the public-private network do not operate in isolation. Each actor is embedded in its own sub-network that influences its behavior and may lead to network effects. The actors within the public-private network are obliged to collectively respond to climate change by demonstrably reducing $\mathrm{CO}_{2}$ emissions and by conducting collective climate protection measures. All members of the public-private network are bound to provide an annual $\mathrm{CO}_{2}$ 
balance sheet to the municipality's climate protection office. This is manifested in a contract signed by the senior mayor and by general managers of Greenock and Jack Fowler.

All actors involved in the public-private network engage in give-and-take exchange relationships with other actors in the network to enable a collective approach to respond to climate change. The network can be described as a mechanism to achieve the municipalities' climate protection doctrine and $\mathrm{CO}_{2}$ reduction scenario for 2020 by building a network of partners that communicate and exchange ideas to collectively respond to climate change. Here, the climate protection office is responsible for promoting climate protection projects within the network and to enable collaboration among all actors. Through knowledge exchange and utilization of synergies the network promotes self-commitment of multinational companies at the local level. Furthermore, a fair competition and mutual encouragement of climate protection measures is apparent between Greenock and Jack Fowler. As we can see, the public-private network is driven by a complex set of interactions due to the diverse, embedded, and interconnected groupings.

\subsection{Conceptual Framework}

Established from our understanding of the literature of collective action and interactions in business networks, and developed further from the case data, we present a conceptual framework to attempt to enable an understanding of the underlying processes that can lead to collective action or inaction (Figure 2). At the core of this iterative process of research (see for example Dubois and Gadde, 2002) is an attempt to understand the lack of collective organizational responses to the overarching challenge of climate change. In order to allow us to do this we apply an interactional perspective to the notion of collective action to tease out some of the ongoing processes and the barriers these interactions face which result in either collective action or inaction. In essence, we take a network perspective to answer the how and why questions outlined above.

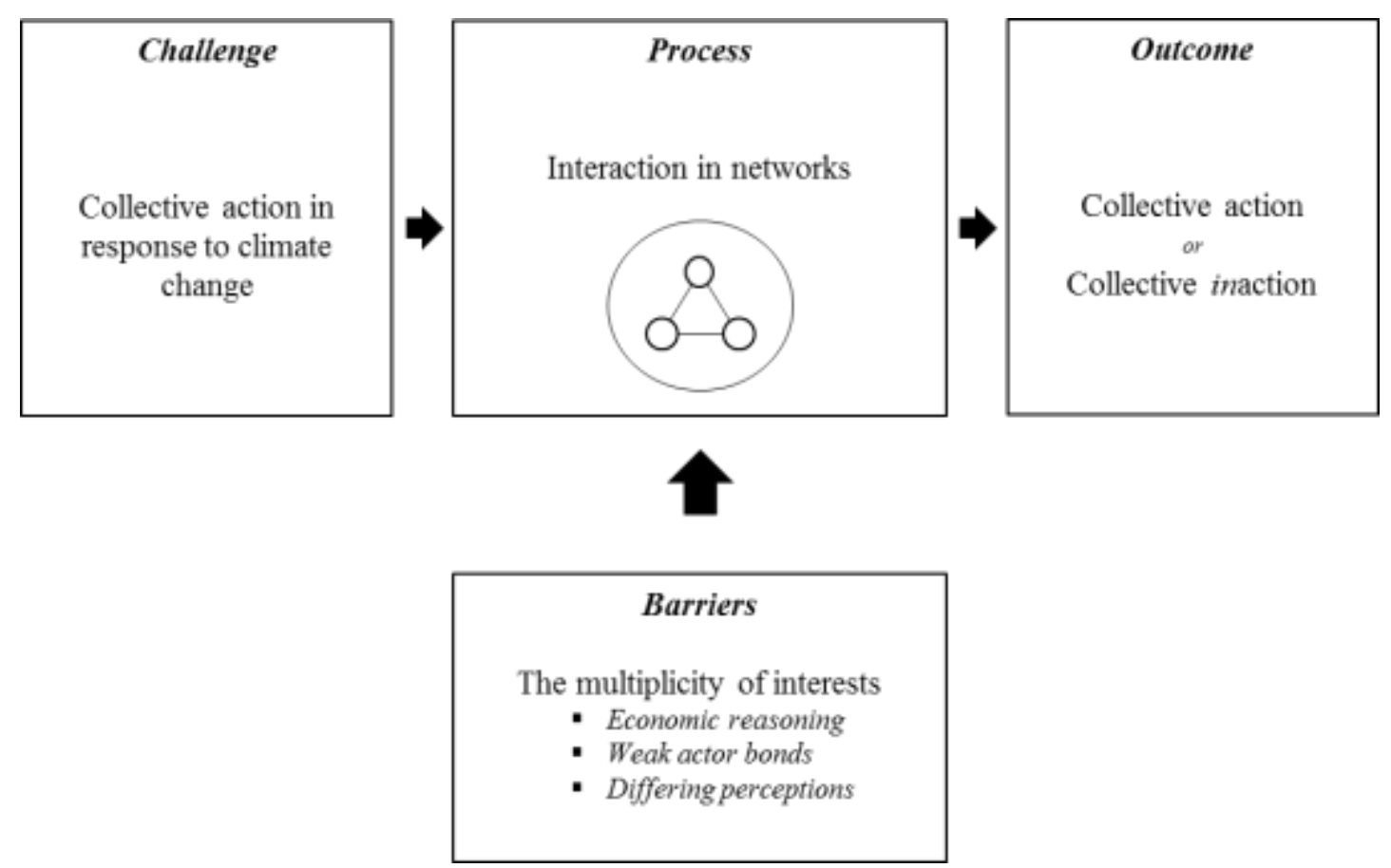

Figure 2: Conceptual framework 


\section{Analysis and discussion}

As outlined in the conceptual framework above, we aim at developing an understanding of how companies interact to craft collective responses to climate and why companies fail to do so. As such, our attention turns to a deeper analysis and discussion of the processes of interaction and crucially what we see as barriers to this and the resulting opportunity for collective action.

We find the overarching barrier to collective responses to climate change is self-interest (Hardin, 1968). Indeed, if we analyze the case data we see that that the interests of each of the key actors in the public-private networks are different and driven by differing perspectives. From a series of detailed conversations with each of the actors in the public-private network, we summarized their quotes on their interests in Table 2 below.



Table 2: Actors' interest in the public-private network 


\subsection{The multiplicity of interests as the key barrier to collective action}

All actors within the public-private network have joined the network based on diverging interests. As illustrated above, each actor is associated with a set of goals that can be similar or different to other actors. The incongruence in goals may even become a stronger barrier when further actors join the public-private network, thus invoking the arguments of scale and diversity of interest (Olson, 1982). Business networks - in their nature - are driven by multiparty interactions in which it is always more difficult to reach consensus due to multiplicity of interests. Climate protection measures that involve multiple parties are disproportionally more difficult to achieve. Here, the traditional behavioral decision theory argues that the incongruence in goals results in increased conflict, poorer communication, and reduced trust, less satisfaction and commitment, and negative views of other disputants (Gelfand et al., 2006).

As the data above suggest, it is the inherent multiplicity of motivations of why they are part of the network and the differing and self-serving reasons of actors with regards to cost savings, image improvements or the protection of resources. These impede the process of interaction within and across the divergent actors within the network, leading to the potential of collective inaction. Below we present three sub-barriers that demonstrate the aggregation and significance of the multiplicity of interest which hinders the successful implementation of collective action.

\subsubsection{Sub-barrier I: Economic reasoning}

As interaction among businesses is driven and maintained for economic reasons (Håkansson, 1982) and if this economic rationality is absent, then business interaction is hindered. Although we can see from the quotes below that Greenock's participation in the network is driven by cost savings from the prospect of energy efficiency, this sentiment was not drawn from comments made by representatives of the municipality Andor who indeed were seen to be more far more driven by achieving their $\mathrm{CO}_{2}$ emissions reduction goal by 2020 .

Harry (Greenock): "Since we are a producing company, we are always looking for the additional $€$ to save. So, it is not just climate change that drives us, but also the topic of cost savings through energy efficiency." [Interview IV, p.1, lines 45-48]

Oliver (Jack Fowler): "The investments always have to bring cost saving in the fastest possible time. I think it has to represent some kind of economic advantage in today's competitive markets." [Panel Discussion, p.4, lines 29-32]

Amelia (Andor): "We have set ourselves an ambitious goal of reducing $\mathrm{CO}_{2}$ emissions by $40 \%$ by 2020 based on the 1990 emissions. This is a good goal and we can achieve this together with the two companies. That why we have started this climate protection initiative." [Panel Discussion, p.2, lines 22-25]

Greenock and Jack Fowler are responding to climate change in a self-serving manner. It seems that they are only investing money, resources and time to interact within the network, when they expect that these interactions are financially or otherwise beneficial. This egoistic and financially beneficial driven behavior impedes collective responses to climate change since the most climate protective project might not be the most financially beneficial. Here, actors' self-interests collide with collective interests which would include Andor. Consequently, developing collective climate protection measures can fail because of economically egoistic behavior of actors. This barrier is related to the issue of immediate costs that occur to respond to climate change and future benefits of climate protection measures. Therefore, network actors tend to focus on low-hanging fruits of immediate cost savings rather than tackling the climate change challenge where it might be most beneficial 
for the environment in the longer run. This is in line with Veal and Mouzas' (2010) argument that climate change mitigation is a rather unattractive solution since immediate costs incur to create benefits that are discounted by the time they can be taken into account.

\subsubsection{Sub-barrier II: Weak actor bonds}

The case data suggest that weak bonds exist among actors. Although Greenock and Jack Fowler do not find themselves competing at the product level, they tend to compete in a mutually respectful manner about who is the most environmentally responsible company within the municipality.

Harry (Greenock): "We do compete to win the prize of the most environmentally friendly company within the region, but we do this in a fair manner." [Interview IV, p.5, lines 10-13]

Furthermore, the case data suggests that a certain degree of suspicion appears to exist in the municipality-company relationship. We argue that the suspicions between the municipality and the companies impede collective responses to climate change. Companies are often concerned about additional regulation and costs when the municipality approaches them regarding the topic of climate change.

Emily (Andor): "The main obstacle is the barrier between companies and the municipality. When we, as the municipality, contacted the companies, they were always concerned about what the intentions of the city are and that we may want to impose additional requirements. It took us quite a while to convince them that we aim for a mutually respectful dialogue and that we do not want to impose additional requirements." [Panel Discussion, p.9, lines 48-52]

Hence, one may conclude that these suspicions and the weak bonds of all actors within the network lead to an inability of influencing the decisions of others in the network. This is supported by the feeling of independency of actors when developing climate protection measures. It appears that business actors' hold a misguided perception that they possess the necessary resources and capabilities to develop a sufficient response to climate change as individual company.

Harry (Greenock): "We are definitely not dependent on the municipality or anyone in the sense that we cannot implement cost-saving or energy efficiency measures. We are certainly not and we do not feel that we are dependent on the municipality." [Interview IV, p.3, lines 33-36]

Emily (Andor): "I do not think that the companies depend on each other. Developing cross-company solutions is very difficult. The easiest solutions are the internal approaches and there are many set screws. They will not save the world, but if everybody contributes a little bit then we already made a big step forward." [Interview IV, p.2-3, lines 51-2]

Although the independency of actors may not hinder the development of individual measures in response to climate change, it may contribute to weaker interpersonal relationships within the network. Consequently, companies may fail to collectively respond to climate change.

\subsubsection{Sub-barrier III: Differing perceptions of the rules of the game}

Structure and the design of rules of the game can influence the way that actors interact with each other (Felin et al., 2012; Veal and Mouzas, 2011). As the quotes below suggest, across the three network actors, they each held different perspectives on what the actual aim of the network was.

Amelia (Andor): "It is important for us to reduce $\mathrm{CO}_{2}$ emissions through the implementation of the climate protection network. " [Panel Discussion, p.8, lines 6-7] 
Oliver (Jack Fowler): "Our expectation of the climate protection network is to use it as a forum that allows us to exchange ideas about climate protection measures. [...] This is supposed to contribute to reach our own climate protection goals." [Panel Discussion, p.10, lines 17-25]

The diverging perceptions of the public-private network impede collective responses to climate change. Those individuals spoken to within Andor perceived the public-private network as a place of congruent goals and interdependency which is supposed to lead to collective action in response to climate change. On the other hand, actors within the Greenock and Jack Fowler perceived it as a place of incongruent goals and independency. Consequently, actors tend to focus on individual responses, whilst failing to collectively respond to climate change. Again, this suggests the negative impact of differing perspective of actors when attempting to craft collective action (Olson, 1982).

\section{Conclusion and implications}

This study was conducted to explore how companies interact in response to climate and why companies fail to collectively respond to climate change. We argued that similarities can exist in terms of the barriers against both collective action and interaction such as scale, diversity of interest and the differing perspective of actors (Olson, 1982) which are inherent in larger collectives or networks. Therefore, we applied a theoretical perspective drawn from the business network literature in order to unveil why collective action does not happen in organizational networks. At the core of this - via the detailed analysis of a public-private network - we identified a set of barriers which, when aggregated, negatively impeded the process of crafting collective action in response to climate change.

This study suggests that the multiplicity of interests is the overarching reason why collective action is impeded. As illustrated above, each actor is associated with a set of goals that can be similar or different to other actors. When actors' goals are incongruent (as illustrated in this case) then reaching consensus on collective climate protection measures is hindered. Here, the traditional behavioral theory states that this incongruence in goals may result in increased conflict, poorer communication, and reduced trust, less satisfaction and commitment, and negative views of other actors (Gelfand et al., 2006). The inherent multiplicity of motivations of why actors are part of a network combined with the differing self-serving reasons of actors with regards to cost savings, image improvements or the protection of resources may be argued to hinder the process of interaction within, and across the divergent actors within the network, leading to the potential of collective inaction.

The multiplicity of interests is aggravated by three sub-barriers that hinder the successful implementation of collective action:

1) Economic reasoning: The interaction among businesses is inherently driven and maintained for economic reasons (Håkansson, 1982). Prior research suggests it seems companies only invest finances, resources and time to interact within the network, when they expect that these interactions are financially or otherwise beneficial. However, actors' self-interests can collide with collective interests which would include wider societal groupings. Therefore, crafting a collective response to climate change can fail because of economically egoistic behavior of actors.

2) Weak actor bonds: Companies are often concerned about additional regulation and costs when being approached by municipalities regarding the topic of climate change. It appears that business actors are suspicious about the intrinsic motivations of the 
municipality. This is amplified by a feeling of independency among actors when developing climate protection measures. This may also be attributed to business managers' misguided perception that they have the necessary resources and capabilities to craft a sufficient response to the global challenge of climate change as individual actors. The suspicions and independent nature of actors promote the development of individual measures in response to climate change. Consequently, network actors may fail to collectively respond to climate change.

3) Differing perceptions of the rules of the game: The structure and design of rules of the game can influence the way that actors interact with each other (Felin et al., 2012; Veal and Mouzas, 2011). It appears that diverging perspectives on what the actual aim of the public-private network is impeded collective responses to climate change. Whereas the municipality perceived the public-private network as a place of congruent goals and interdependency, both companies perceived its goals as incongruent goals and its actors as independent. The negative impact of diverging perspectives of actors involved in the network impedes the endeavor of crafting collective responses to climate change.

In an attempt to overcome the barriers presented above one may suggest that a fundamental shift from self-interested and financially driven behavior of actors is necessary to allow the development of sufficient measures to tackle the global challenge of climate change.

However, from our analysis of the data, we posit that this is a highly unlikely scenario as it stands. We argue that if firms and organizations intend to develop collective responses to climate change, it is a prerequisite for these firms to have a clear understanding of what the goals, motivations and interests of each organizational actor involved are. We suggest that by taking actors' financial, economic and altruistic notions into account when designing networks for collective action, the multiplicity of interests among actors can be downscaled. Therefore, we conclude that the resulting congruence of goals, motivations and interests of each organizational actor would enable the success of collective action and reduce the chances of collective inaction. 


\section{References}

Bazerman, M.H., 1984. The relevance of Kahneman and Tversky's concept of framing to organizational behavior. Journal of Management, 10, pp.333-343.

Bazerman, M.H., Moore, D.A. and Gillespie, J.J., 1999. The Human Mind as a Barrier to Wiser Environmental Agreements. American Behavioral Scientist, 42(8), pp.12771300 .

Bennet, A. and Elman, C., 2006. Complex causal relations and case study methods: The example of path dependence. Political Analysis, 14, pp.250-67.

Brown, L., 1996. State of the World. Worldwatch Institute, New York.

Dubois, A., 1998. Organising Industrial Activities Across Firm Boundaries. London: Routledge.

Dubois, A. and Gadde, L.-E., 2002. Systematic combining: an abductive approach to case research. Journal of Business Research, 55(7), pp.553-560.

Easton, G. and Araujo, L., 1994. Market Exchange, Social Structures and Time. European Journal of Marketing, 28(2), pp.72-84.

Easton, G. and Håkansson, H., 1996. Markets as networks: Editorial introduction. International Journal of Research in Marketing, 13, pp.407-13.

Easton, G., 2010. Critical realism in case study research. Industrial Marketing Management. 39(1), pp.118-28.

Felin, T., Foss, N.J., Heimeriks, K.H. and Madsen, T.L., 2012. Microfoundations of routines and capabilities: Individuals, processes, and structure. Journal of Management Studies, 49(8), pp.1351-1374.

Ford, D. and Håkansson, H., 2006. The idea of interaction. IMP Journal, 1(1), 4-27.

Ford, D., Gadde, L-E., Håkansson, H., Snehota, I. and Waluszewski, A., 2008. Analysing Business Interaction. IMP Conference.

Ford, D. and Mouzas, S. 2010. Networking under uncertainty: Concepts and research agenda. Industrial Marketing Management, 39(6), pp.956-962.

Ford, D. and Mouzas, S. 2013. The theory and practice of business networking. Industrial Marketing Management, 42(3), pp.433-442.

Gelfand, M., Major, V., Raver, J., Nishii, L. and O'Brien, K., 2006. Negotiating relationally: the dynamics of the relational self in interactions. Academy of Management Review, 31(2), pp.427-451.

George, A.L. and Bennett, A., 2005. Case studies and theory development in social sciences. London: MIT Press.

Giddens, A., 2009. The Politics of Climate Change. Cambridge: Polity Press. 
GlobeScan, 2006. Formative research for the Climate Forum: a survey of sustainability experts and in-depth interviews with climate change solution providers. Toronto: GlobeScan.

Gnyawali, D.R. and Madhavan, R., 2001. Cooperative networks and competitive dynamics: Structural embeddedness perspective. Academy of Management Review, 26(3), pp.43145 .

Håkansson, H., (ed.), 1982. International Marketing and Purchasing of Industrial Goods: An Interaction Approach. Chichester: John Wiley.

Håkansson, H. and Johanson, J., 1992. A Model of Industrial Networks. In Axelsson, B. and Easton, G. (eds.). Industrial Networks: A New View of Reality. London: Routledge.

Håkansson, H. and Snehota, I., 1995. Developing Relationships in Business Networks. London: International Thomson.

Håkansson, H. and Johanson, J., 2001. Business Network Learning. Amsterdam: Pergamon.

Håkansson, H. and Ford, D., 2002. How should companies interact in business networks? Journal of Business Research, 55, pp.133-39.

Håkansson, H. and Waluszewski, A., 2002. Managing technological development: IKEA, the environment and technology. London: Routledge.

Håkansson, H. and Waluszewski, A. eds., 2007. Knowledge and innovation in business and industry: The importance of using others. London: Routledge.

Halinen, A. and Törnroos, J.-A., 2005. Using case methods in the study of contemporary business networks. Journal of Business Research, 58, pp.1285-97.

Hallen, L., Johanson, J., Seyed-Mohammed, N., 1991. Interfirm adaptation in business relationships. Journal of Marketing, 55(2), pp.29-37.

Hardie, I. and MacKenzie, D., 2007. Constructing the market frame: Distributed cognition and distributed framing in financial markets. New Political Economy, 12, pp.389-403.

Hardin, G.,1968. The tragedy of the commons. Science, 162(3859), pp.1243-48.

Huemer, L., 1998. Trust in Business Relations. Economic Logic or Social Interaction. Umea: Borea.

Intergovernmental Panel on Climate Change (IPCC), 2001. Climate Change 2001: Synthesis Report, Summary for Policymakers. Geneva: Intergovernmental Panel on Climate Change.

Intergovernmental Panel on Climate Change (IPCC), 2014. Climate Change 2014: Impacts, Adaptation, and Vulnerability, Summary for Policymakers. Cambridge: Cambridge University Press.

Lazonick, W., 1991. Business Organization and the Myth of the Market Economy. Cambridge: Cambridge University Press.

Leiserowitz, A., 2006. Climate change risk perception and policy preferences: The role of affect, imagery, and values. Climatic Change, 77(1), pp.45-72. 
Meehl, G.A., Stocker, T.F., Collins, W.D., Friedlingstein,, P., Gaye, A.T., Gregory, J.M., Kitoh, A., 2007. Global climate projections. Climate Change, 3495, pp.747-845.

Mouzas, S., 2006. Efficiency versus effectiveness in business networks. Journal of Business Research, 59(10-11), pp.1124-1132.

Mouzas, S. and Ford, D., 2009. The constitution of networks. Industrial Marketing Management, 38, pp.495-503.

Nowak, M. and Highfield, R., 2011. Super Cooperators: Altruism, Evolution, and Why We Need Each Other to Succeed. New York: Free Press.

Numamgami, T., 1998. The infeasibility of invariant laws in management studies: A reflective dialogue in defense of case studies. Organization Science, 9, pp.2-15.

Okereke, C., 2007. An Exploration of Motivation, Drivers and Barriers to Carbon Management: The UK FTSE 100. European Management Journal, 25(6), pp.475-486.

Olson, M., 1965. The Logic of Collective Action. Public Goods and the Theory of Groups. Cambridge: Harvard University Press.

Olson, M., 1982. The Rise and Decline of Nations: Economic Growth, Stagflation, and Social Rigidities. New Haven: Yale University Press.

Oreskes, N., 2004. The scientific consensus on climate change. Science, 306(5702), pp.16861686.

Pendergraft, C.A., 1998. Human dimensions of climate change: Cultural theory and collective action. Climatic Change, 39, pp.643-666.

Perry, C., 1998. Processes of a case study methodology for postgraduate research in marketing. European Journal of Marketing, 32, pp.785-802.

Ragin, C. and Becker, H., 1992. What is a case? Exploring the foundations of social inquiry. Cambridge: Cambridge University Press.

Richardson, G., 1972. The Organisation of Industry. Economic Journal, 82, pp.883-896.

Ritter, T., 2000. A Framework for Analyzing Interconnectedness of Relationships. Industrial Marketing Management, 29, pp.317-26.

Ritter, T. and Gemünden, H.G., 2003. Interorganizational relationships and networks: an overview. Journal of Business Research, 56, pp.691-697.

Ritter, T., Wilkinson, I.F. and Johnston, W.J., 2004. Managing in complex business networks. Industrial Marketing Management, 33, pp.175-183.

Stern, N., 2006. Stern Review: The Economics of Climate Change. London: HMSO.

Sunstein, C.R., 2006. The availability heuristic, intuitive cost-benefit analysis, and climate change. Climatic Change, 77, pp.195-210.

Turnbull, P.W. and Valla, J-P., 1986. Strategies for International Industrial Marketing: The Management of Customer Relationships in European Industrial Markets. London: Croom Helm. 
Tversky, A. and Kahneman, D., 1981. The framing of decisions and the psychology of choice. Science, 211, pp.453-458.

Tversky, A. and Kahneman, D., 1986. Rational choice and the framing of decisions. Journal of Business, 59, pp.251-78.

Veal, G. and Mouzas, S., 2010. Learning to collaborate: a study of business networks. Journal of Business \& Industrial Marketing, 25(6), pp.420-34.

Veal, G. and Mouzas, S., 2011. Changing the rules of the game: Business responses to new regulation. Industrial Marketing Management, 40, pp.290-300.

Veal, G. and Mouzas, S., 2012. Market-Based Responses to Climate Change: $\mathrm{CO}_{2}$ Market Design versus Operation. Organization Studies, 33(11), pp.1-28.

Wade-Benzoni, K.A., Hoffman, A.J., Thompson, L.L., Moore, D.A., Gillespie, J.J. and Bazerman, M.H., 2002. Barriers to Resolution in Ideologically Based Interactions : The Role of Values and Institutions. Academy of Management Review, 27(1), pp.41-57.

Welch, C. and Wilkinson, I., 2004. The political embeddedness of international business networks. International Marketing Review, 21(2), p.216-231.

Wilkinson, I. and Young, L., 1994. Business dancing - the nature and role of interfirm relations in business strategy. Asia-Australia Marketing Journal, 2(1), pp.67-79.

Wilson, D.T. and Jantrania, S., 1994. Understanding the Value of a Relationship. AsiaAustralia Marketing Journal, 2(1), pp.55-66.

Yin, R.K., 2003. Case study research: Design and methods. 3rd Edn. London: Sage. 